\title{
PREFACE: TECHNICAL COMMISSION IV
}

\author{
Sisi Zlatanova ${ }^{1}$, Suzana Dragicevic ${ }^{2}$, George Sithole $^{3}$ \\ ${ }^{1}$ President, University of New South Wales, Sidney, Australia - s.zlatanova@unsw.edu.au \\ ${ }^{2}$ Vice President, Simon Fraser University, Burnaby, Canada - suzanad@sfu.ca \\ ${ }^{3}$ Secretary, GeoVariant, Cape Town, South Africa - georgesithole@geovariant.com
}

\begin{abstract}
The world is facing the second year of the Covid-19 global pandemic that has affected many around the world. Despite the challenges, ISPRS is organizing its second consecutive virtual Congress to motivate, inspire and connect geospatial researchers around the globe to share the knowledge and communicate their research results. This year Commission IV shares the successful research endeavours of many members of working groups and their graduate students and research teams.
\end{abstract}

In the years since the XXIII ISPRS congress, 2016, there have been many important developments. Managing the social and economic challenges brought by increased complexity and interconnectivity of activities in human society requires new dimensions of analysing information and specifically spatial information. The increased pressure on the usage of geographic space, maintaining sustainable development and creating liveable community environments increases the requirements for spatial decision-making tools. The last years of Covid-19 restrictions and lockdowns pose a range of new challenges to spatial information such as occupancy estimations, efficient use of building space and safe navigation within buildings. The focus on dynamic changes and analysing real-time sensor data is increasing. The developments of Spatial Digital Twins are maturing in the context of providing tools and methods for high density human settlements to be more resilient, sustainable, liveable, and safe.

Commission IV Spatial Information Science (2016-2022) is dedicated to advance research activities in spatial information sciences for modelling, structuring, management, analysis, visualization and simulation of (big) data with focus on the third spatial dimension and taking into consideration dynamic changes. Special attention is given to linking information about real-world physical phenomena with societal, governmental, organizational and legal information in order to address the complexity of issues in their entirety. The Commission has contributed to advancements in data modelling, data fusion and management, visualization (web-based, VR and AR), simulation and city analytics, and 3D applications. The work had largely been implemented in cooperation with international organizations such as FIG, UDMS, 3DGeoinfo, ICA, OGC, ISO and Web3D.

The Commission consists of 10 scientific areas of research that is coordinated by 10 working groups (WG) and one inter commission working group (ICWG) as follows - WG1: Multidimensional spatial models; WG2: Ontologies, semantics and knowledge representation for geospatial information; WG3: Spatial data analysis, statistic and uncertainty modelling; WG4: Collaborative crowdsourced cloud mapping $\left(\mathrm{C}^{3} \mathrm{M}\right)$; WG5: Indoor/outdoor seamless modelling, LBS and mobility; WG6: SDI: Internet of things and spatial decision support; WG7: Geo-data management; WG8: Geo-computation and geo-simulation; WG9: Geovisualisation, augmented and virtual reality; WG10: Advanced geospatial applications for smart cities and regions; ICWG IV/III: Global mapping: updating, verification and interoperability.

The papers received for the ISPRS virtual event reflect the above-mentioned scientific research areas. The reported research ranges from advancements in new and emerging theories, through experiments and analysis to demonstration of technologies in different applications. The research was captured through papers and abstracts published in the collection of ISPRS Annals and ISPRS Archives. The ISPRS Annals contain 24 papers and the ISPRS Archives contain 56 papers. The diversity of the research presented in the published papers clearly indicates the wide range of topics within the field of Spatial Information Science. A rigorous peer-review process by the ISPRS TC IV Scientific Committee contributed to high quality proceedings.

In closing we would like to note the commission's plans for the upcoming year. Because the pandemic has forced many to work remotely, we have been motivated to find new ways to remain informed of changes in the work of the commission and working groups. The commission plans to host monthly webinars at which working groups can showcase their activities and achievements. We hope that this will generate greater interest in the work of the commission and enhance the profile of the commission's working groups. 


\section{TC IV Scientific Committee}

Giorgio Agugiaro, Delft University of Technology, Delft the Netherlands, Jamal Jokar Arsanjani, Aalborg University, Aalborg, Denmark, Pawel Boguslawski, Wroclaw University of Environmental and Life Sciences, Wroclaw, Poland, Martin Breunig, Karlsruhe Institute of Technology, Karlsruhe, Germany, Maria Antonia Brovelli, Politecnico di Milano, Milan, Italy, Sidonie Christophe, Univ. Gustave Eiffel, IGN-ENSG France, LASTIG, Paris, France, Arzu Coltekin, University of Applied Sciences and Arts Northwestern Switzerland, Windisch, Switzerland, Mahmoud R. Delavar, University of Tehran, Tehran, Iran, Mulhim Al Doori, University of Fujairah, Fujairah, UAE, Suzana Dragicevic, Simon Fraser University, Burnaby, Canada, Eric Guilbert, Université Laval, Québec, Canada, Cidalia Costa Fonte, University of Coimbra, Coimbra, Portugal, James Haworth, University College London, London, United Kingdom, Umit Isikdag Mimar Sinan, Fine Arts University Istanbul, Istanbul, Turkey, Ivana Ivanova, Curtin University, Perth, Australia, Zhizhong Kang, China University of Geosciences, Beijing, China, Kourosh Khoshelham, University of Melbourne, Melbourne, Australia, Mila Koeva, University of Twente, Enschede, The Netherlands, Margarita Kokla, National Technical University of Athens, Athens, Greece, Yaolin Liu, Wuhan University, Wuhan, China, Marguerite Madden, University of Georgia, Athens, Georgia, USA, Mir Abolfazl Mostafavi, Université Laval, Quebec, Canada, Gerhard Navratil, Technical University Wien, Vienna, Austria, Dev Raj Paudyal, University of Southern Queensland, Toowoomba, Australia, Christopher Pettit, University of New South Wales, Sydney, Australia, Antonia Spano, Politecnico di Torino, Italy, George Sithole, GeoVariant, Cape Town, South Africa, Emmanuel Stefanakis, University of Calgary, Calgary, Canada, Wei Tu, Shenzhen University, Shenzhen, China, Giuseppina Vacca, University of Cagliari, Cagliari, Italy, Lucia Diaz Vilarino, University of Vigo, Vigo, Spain, Sarah Wise, University College London, London UK, Hao Wu, National Geomatics Center of China, Beijing, China, Sisi Zlatanova, University of New South Wales, Sydney, Australia, Xiao Guang Zhou, Central South University, Changsha, Hunan China. 